\title{
BISHOP'S PROPERTY $(\beta)$ FOR PARANORMAL OPERATORS
}

\author{
ATSUSHI UCHIYAMA AND KOTARO TANAHASHI
}

Abstract. For an operator $T$ on a separable complex Hilbert space $\mathscr{H}$, we say that $T$ has Bishop's property $(\beta)$ if for any open subset $\mathscr{D} \subset \mathbb{C}$ and any sequence of analytic functions $f_{n}: \mathscr{D} \rightarrow \mathscr{H}$ such as $\left\|(T-z) f_{n}(z)\right\| \rightarrow 0$ as $n \rightarrow \infty$ uniformly on every compact subset $\mathscr{K} \subset \mathscr{D}$, then $f_{n} \rightarrow 0$ uniformly on $\mathscr{K}$. It is a very important property in spectral theory. It is well-known that every normal operator $\left(T^{*} T=T T^{*}\right)$ has Bishop's property $(\beta)$. Now, many mathematicians attempt to extend this result to non-normal operators.

In this paper, we shall show that every paranormal operator $\left(\left\|T^{2} x\right\|\|x\| \geqslant\|T x\|^{2}\right.$ for all $x \in \mathscr{H}$ ) has Bishop's property $(\beta)$.

Mathematics subject classification (2000): 47B20.

Keywords and phrases: Bishop's property $(\beta)$, paranormal operator.

\section{REFERENCES}

[1] A. Aluthge, On p-hyponormal oprators for $0<p<1$, Integral Equations and Operator Theory, 13 (1990), 307-315.

[2] A. AluthGE AND D. WANG, w-hyponormal oprators , Integral Equations and Operator Theory, 36 (2000), 1-10.

[3] M. Chō And T. HuruYA, p-hyponormal oprators for $0<p<\frac{1}{2}$, Comment Math., 33 (1993), $23-29$.

[4] M. СHō AND T. YAMAZAKI, An operator transform class A to the class of hyponormal operators and its application, Integral Equations and Operator Theory, 53 (2005), 497-508.

[5] T. Furuta, On the class of paranormal operators, Proc. Japan Acad., 43 (1967), 594-598.

[6] T. FurUtA, M. ITO AND T. YAMAZAKI, A subclass of paranormal operators including class of log -hyponormal and several related classes, Sci. Math., 1 (1998), 389-403.

[7] V. Istrăţescu, T. Saitō And T. Yoshino, On a class of operators, Tôhoku Math. J., (2), 18 (1966), 410-413.

[8] F. Kimura, Analysis of non-normal operators via Aluthge transformation, Integral Equations and Operator Theory, 50 (2004), 375-384.

[9] K. B. Lausen, Operators with finite ascent, Pacific J. Math., 152 (1992), 323-336.

[10] A. UchiyAma, Weyl's theorem for class A operators, Math. Inequal. \& Appl., 4 (2001), 143-150.

[11] A. Uchiyama, K. Tanahashi And J. I. Lee, Spectrum of class A(s,t) operators, Acta Sci. Math. (Szeged), 70 (2004), 279-287.

[12] D. XIA, On the non-normal operators-semihyponormal operators, Sci. Sinica., 23 (1980), 700-713. 